\title{
CONVERSANDO CON CARMEN NARANJO ${ }^{1}$
}

\author{
POR \\ ROSE S. MINC \\ Montclair State College \\ $\mathbf{Y}$ \\ TERESA MENDEZ-FAITH \\ Brandeis University
}

RSM/TMF: Carmen, ¿cuál es tu opinión con respecto a la posición de la escritora latinoamericana en el contexto histórico-político actual?

$\mathrm{CN}$ : Pienso que la escritora latinoamericana debe estar comprometida con la realidad social en la que vive. En el campo de la expresión, yo la veo como una mujer absolutamente libre, que puede o no escribir sobre esa realidad. Culturalmente, la mujer debe estar comprometida con la mujer misma. Me explico: siendo la cultura patrimonio universal que ha traído tantos bienes, tantas cosas buenas, la verdad es que al mismo tiempo ha transmitido prejuicios sobre la mujer. Entonces, ésta tiene que estar muy alerta para que esos prejuicios no se sigan transmitiendo e incluso para que se cambien determinados patrones culturales que en estos momentos la perjudican. rica?

RSM/TMF: ¿Ves esto reflejado, de alguna manera, en Centroamé-

$\mathrm{CN}$ : En Centroamérica, la mujer está absolutamente comprometida con sus pueblos, con sus luchas de reivindicación. Lamentablemente, aquí hay muchas mujeres que, por las condiciones de amenaza de gobiernos

${ }^{1}$ Carmen Naranjo, poetisa, ensayista, dramaturga y novelista, es una de las intelectuales más importantes de Costa Rica. Su valiosa producción incluye, entre otros, los siguientes títulos: Canción de la ternura (poesía), Misa a oscuras (poesía); Los perros no ladraron (novela, Premio Nacional, 1966), Responso por el niño Juan Manuel (novela, premiada en Guatemala, 1968), Diario de una multitud (novela), y Ondina (colección de cuentos, Premio Educa, 1982). Además de sus actividades estrictamente literarias, la autora se destaca también por su fecunda labor en el campo social y en el marco más amplio de la cultura y del arte de su país. Nuestra conversación con Carmen Naranjo tuvo lugar en San José, Costa Rica, en julio de 1984, durante las jornadas del Segundo Simposio Internacional de Literatura: Evaluación de la Literatura Femenina de Latinoamérica. 
militares, no pueden vivir en sus países y están en el exilio. Por ejemplo, hay casos de guatemaltecas, casos de salvadoreñas y hay unos pocos casos de hondureñas también. Pero las demás mujeres, las que están dentro de sus países, como las nicaragüenses que están trabajando con la revolución, están realmente haciendo una labor de gran solidaridad con su país. Yo les confieso que no conozco - y tal vez no hay - ninguna mujer artista centroamericana que no esté comprometida con su realidad.

RSM/TMF: Con relación a esto, una de las preocupaciones repetidamente expresadas por la crítica es el hecho que se espera que las escritoras -en sus textos - tomen no solamente una posición política de inmediatez histórica, sino que también, a partir de ella, avancen una o más soluciones a la problemática existente. ¿Qué puedes decirnos a este respecto?

$\mathrm{CN}$ : Yo en eso soy terriblemente libre. Yo no creo que la obra literaria tenga que estar comprometida también. Es la persona la que debe estar comprometida. No se puede "producir» poemas políticos, ya que lo que sale son panfletos, cosas espantosas que afectan la labor literaria del autor. En mi caso personal, sólo he escrito un poema político, político de inmediatez, digamos. Se titula «Guatemala: Una ventana abierta a la muerte», y lo escribí cuando desapareció Alaíde Fopa, el 19 de diciembre de 1980. Me golpeó tanto, me dio tan duro: una mujer humanista, una guatemalteca excelente que desapareciera en esa forma... Fue la única vez que yo he podido escribir un poema así, de inmediatez política. En cuanto a avanzar soluciones a la problemática existente, en eso no creo. Eso sería exigir demasiado. El compromiso quizá salga de la obra, quizá no. Se está trabajando con texturas, con el lenguaje, con la trama, con tanta cosa, que todavía exigir algo más -y soluciones, sobre todo- me parece muy injusto.

RSM/TMF: Si consideramos varios de los artículos publicados recientemente en torno a obras de escritoras, parecería que se juzga el valor estético de esa producción exigiendo una conciencia social y política que no se requiere de los colegas masculinos. En el caso específico de La casa de los espiritus, de Isabel Allende, por ejemplo, se criticó como falla técnica que la narradora, Alba, no ofreciera una clara y abierta posición feminista de vanguardia. Pero, a nuestro entender, jamás se exigió al último de los Buendía, el de la cola de cerdo, que avanzara ninguna solución, ¿verdad?

CN: Tienen toda la razón. Yo me imagino a Isabel manejando una trama tan delicada como la de La casa de los espíritus, cerrando ciclos, abriendo otros, buscando todos los antecedentes históricos, escarbándose ella misma para dar la obra - ihay que ver lo desgastador que es una 
obra!-, y todavía exigirle cierta profecía política dentro de su creación..., ino!, jeso ya es el colmo! Y como dicen muy bien, a García Márquez no se le ha exigido eso. Volviendo momentáneamente a mi caso personal, yo escribí mi primera novela sobre la burocracia, un tema eterno. $Y$ cuando me enfrenté a los críticos, me exigían una solución. Me dijeron: «Usted pintó el panorama excelentemente bien. Ese es el panorama. Pero ¿qué solución da usted?» ¿Cómo iba yo a dar una solución a una cosa tan vieja, de que padece el capitalismo, de que padece el socialismo, de que padece el comunismo, como es la burocracia? Y eso es lo que me exigían en la novela. iMe parecía tan injusto...!

RSM/TMF: En efecto, a la mujer se le pide lo que nunca se le ha pedido a los hombres...

$\mathrm{CN}$ : Claro. A las mujeres se les pide toda una serie de acrobacias: tienen que ser guapas, tienen que andar todo el tiempo bien vestidas, trabajar como animales y demostrar -en todo momento- una capacidad superior. No se puede errar. Una se siente como un acróbata exagerado, como en un circo. Y esto pasa también en la literatura.

RSM/TMF: ¿Crees que hay diferencias significativas entre la literatura escrita por mujeres en Latinoamérica y la producida en Europa?

$\mathrm{CN}$ : Yo sí creo que hay diferencias, y son diferencias culturales, puntos de vista distintos, experiencias personales diferentes. Incluso hay más literatura sobre literatura en Europa, y hay más literatura sobre realidad en Latinoamérica.

RSM/TMF: En tu opinión, ¿qué es lo que separa los textos de las escritoras latinoamericanas de hoy?

$\mathrm{CN}$ : Creo que lo que separa más en América Latina es el desconocimiento que tenemos de esos textos. La prueba está en que tenemos que llegar a un simposio como éste para conocer lo que están haciendo Isabel Allende, o Luisa Valenzuela, o Albalucía Angel, o lo que ha hecho Luisa Mercedes Levinson idesde hace años! Eso es lo que más nos separa.

RSM/TMF: Y לhay algo que una a América Latina?

$\mathrm{CN}$ : Miren, sobre América Latina hay una cierta estrategia de silencio. Se conoce nuestra violencia. Se conoce nuestra tragedia. Pero no se conoce la labor cultural que tenemos, la labor creativa, la imaginación, el valor de las mujeres.

RSM/TMF: En el caso específico de la literatura, ¿hay alguna temática o estrategia textual que la mujer pueda agregar a la ya existente?

$\mathrm{CN}$ : Claro. Su punto de vista. Su punto de vista sobre el mundo, su forma de ver las cosas.

RSM/TMF: ¿Dirías que ese punto de vista es muy diferente al masculino? 
$\mathrm{CN}$ : Es que la mujer tiene $s u$ punto de vista. La mujer toma la palabra y, un poco como decía Luisa Mercedes Levinson, la escribe con su cuerpo. $Y$ ese cuerpo tiene una energía sexual distinta a la del hombre. Por tanto, hay un punto de vista propio, diferente al del hombre, y yo defiendo mucho ese punto de vista. Pienso que la mujer tiene que dejar de ver por los ojos del hombre. Hasta este momento, ése ha sido siempre el caso. Y lo hemos visto aquí. ¿Qué reconocimiento se espera? Pues que Borges diga que una es escritora. Entonces sí se siente una realizada. Pero si Luisa Mercedes Levinson dice lo mismo, ¿por qué no sentirse igualmente realizada?

RSM/TMF: ¿Podemos separarnos con una nota optimista?

$\mathrm{CN}$ : Depende de tantas circunstancias la vida... Yo no quiero ser pitonisa, y no sé qué va a pasar. Estamos viviendo días muy inciertos, pero creo que pasado este momento de peligro, y si tomamos las prevenciones para unirnos más y más, en alguna forma se va a lograr esa unidad. Yo inicié este encuentro diciendo que éramos muy pocas y estábamos muy solas, pero creo que ahora se ha despertado entre todas un espíritu de solidaridad tal que ya no somos ni tan pocas ni estamos tan solas. 